\title{
Empathy in Language Learning and Its Inspiration to the Development of Intercultural Communicative Competence
}

\author{
Chao Chen \\ School of Foreign Languages, Qingdao University of Science and Technology, Qingdao, China
}

\begin{abstract}
In intercultural communication misunderstandings between communicators will appear. It is quite necessary to improve learners' communicative competence. The term "communicative competence" first gained wide exposure in the writings of Hymes (1971). He argued that communicative competence must include the linguistic forms of a language and the knowledge of when, how and to whom it is appropriate to use these forms. There are some necessary conditions before we are competent in intercultural interactions. These conditions include knowledge about the people in other cultures, the communication rules, and the context governing the interaction with the member of the other culture, etc. In many definitions of empathy, the idea of "acquiring another person's perspective" is crucial. It is this sense that is supposed to contribute a lot to achieving effective intercultural communication. We are supposed to be clear of the ways of improving empathy ability, among which understanding who we are culturally is the first step to becoming empathetic towards other cultures. The second step is to realize the differences between one's own culture and foreign cultures. This thesis only covers a very limited aspect of this issue, and it is expected by the author that the exploration may become further and further.
\end{abstract}

Index Terms - empathy, intercultural communication, communicative competence

\section{THE CONCEPT OF EMPATHY}

The concept of empathy is comparatively new and it has aroused a lot of discussions about its definition. Since it has been used in different fields such as aesthetics, psychology, linguistics and pragmatics, it is necessary to give the different understandings of this concept first.

\section{A. Empathy as an Interpersonal Phenomenon}

It is hard to define a specific concept, and it is the same case with the concept "empathy". The word "empathy" has been troublesome since it entered the language of psychology and psychiatry. The word empathy is not in the complete Oxford English Dictionary, though it is in a more recent edition (Simpson \& Weiner, 1989). The most recent OED defines empathy as:

The power of projecting one's personality into, and so fully understanding the object of contemplation.

The term empathy has come to be widely adopted ever since, first in psychology and then more generally. In 1897, Lipps introduced the term "Einfühlung" in his writings about aesthetic perception and appreciation. "Einfühlung" meant "feeling oneself into" in German, and was translated as "empathy" by Tichener in 1910. Lipps believed that, in examining and contemplating an object (e.g., of art, nature, etc.), people projected themselves into the object, established an identification between the object and oneself, engaged in a process of inner imitation, and in this way came to a much better understanding and appreciation of the object, and Lipps called this "practical empathy".

Some years later, Lipps (1926, cited in Yang Yue's Thesis) extended this definition to include people. According to him, the perceiver engages in imitating the target object or person by consciously or unconsciously assuming aspects of its posture and, in the case of target persons, taking on certain of his or her physical stances, gestures, or expressions. In this manner, inner cues are created in the perceiver that leads to a heightened appreciation and understanding of the object/person and, in the case of target persons, a shared feeling experience. Thus, for Lipps, empathy proceeded by means of projection and imitation, could involve either objects or persons as targets, and consisted largely of heightened understanding of the other through cue-produced shared feelings.

With the introduction of Lipps, numerous scholars from various fields of study began to show great interest in the concept of empathy, and have developed quite many different definitions. With the work of George Mead (1934, ibid.), the definitional focus of empathy shifted in two important directions. A cognitive component in the form of "an ability to understand" was added to the earlier affective emphasis. Furthermore, the blending or merging of identities notion yielded to a self-other differentiation in which the empathizer temporarily "took the role of the other" or "put themselves in the other's place" as the heart of the empathic process.

Now in many definitions of empathy, the idea of acquiring another person's perspective is crucial. As pointed out by Bohart and Greenberg (1977, ibid.), most definitions of empathy include the idea of "trying to sense, perceive, share, or 
conceptualize how another person is experiencing the world".

From the above definitions, we may view empathy as an interpersonal phenomenon, which includes that (1) the empathizer understands the target's situation and emotions, (2) the target experiences one or more emotions, (3) the empathizer perceives the similarity between what the target is experiencing and something the empathizer has experienced previously, and (4) the empathizer is concerned for the target's well-being.

There is one more thing worth mentioning about empathy, i.e., no communicators will show empathy from the right beginning of their communication. It needs studying and time, namely, a process to understand and to acquire.

\section{B. Lingua-pragmatic Empathy}

The notion of empathy was firstly introduced into linguistics by Susumu Kuno, a well-known Japanese linguist. Then he develops a theory of empathy in syntax by virtue of the following observations. He first explains the notion of point of view in terms of an informal notion of 'camera angle'. Thus, given a man and his brother, John and Bill, and that the former hit the latter, the speaker can describe this event in various ways, which include (1a) to (2c):

(1) a. Then John hit Bill.

b. Then John hit his brother.

c. Then Bill's brother hit him.

(2) ${ }^{1}$ a. Then Bill was hit by John.

b. ?? Then John's brother was hit by him.

?? Then his brother was hit by John.

c. Then Bill was hit by his brother.

All the above sentences are identical in their logical content, but they seem to differ from each other with respect to where the speaker has placed himself in relation to John and Bill, i.e. these sentences differ from each other in camera angles.

One of the most important decisions that directors must make is where to place the camera while shooting this scene in which John hit Bill. The scenes shot from different camera angles, while capturing the same act of John's hitting Bill, produce different effects on the viewer. In describing the event in which John hit his brother Bill, speakers can place themselves in the following different assumptions:

(1-a) is the most objective sentence, in which the speaker is not taking sides either with John or Bill. In terms of camera angle discussed above, the directors place the camera equidistant from both John and Bill.

With respect to (1-b) statement, the speaker has placed himself closer to John than to his brother. This is shown by the fact that the speaker has chosen the term John's brother (his brother) in referring to Bill; the term John's brother does not give Bill an independent characterization, but a characterization that is dependent upon John.

In the same way, the expression Bill's brother (or his brother) can be used only when the speaker has placed himself closer to Bill than to John. Thus, (1-c) and (2-c) are sentences that the speaker has produced by placing himself closer to Bill than to John.

With respect to (2-a), a passive sentence, it signified speaker placement closer to the new subject than to the old.

Thus, (2-a) and (2-c) are both sentences in which the speaker is placed closer to Bill than to John.

What is most interesting here is that, the sentences of (2-b), repeated below, are marginal:

(1) a.?? Then John's brother was hit by him.

b.?? Then his brother was hit by John.

The above phenomenon is predictable on the basis of the two observations that Kuno has made about camera angles. The term John's brother (or his brother), according to the first observation, indicates that the speaker has placed himself closer to John than to Bill. On the other hand, the use of the passive sentence pattern, according to the second observation, signified that the speaker has placed himself closer to the referent of the new subject, Bill, than to the referent of the old subject, John. These two positions are mutually irreconcilable, and clearly cannot be occupied by a single speaker/camera. The fact that the sentences of (3) are marginal suggests that in producing a single sentence the speaker can use only one "camera". Just as a film director must choose a single camera position for a given scene, the speaker must predetermine his camera position and maintain that position through the production of a single sentence. Thus, the consideration of camera angles or points of view in sentence production makes it possible to account for the marginality of (3), which would be unexplainable otherwise.

In the light of the above observations, Kuno develops a theory of "empathy". Now, let's take a look at the following definition offered by Kuno:

Empathy is the speaker's identification, which may vary in degree, with a person/thing that participates in the event or state that he describes in a sentence.

In this sense the concept empathy is mainly applied by Kuno to explain sentence structures. Nowadays, empathy is more often used in verbal communication, and then in cross-cultural communication.

Empathy is a type of communicative behavior that is closely related to cognitive processes. Without empathy, communication as a form of negotiation cannot take place. Although empathy originally belongs to the domain of

\footnotetext{
1 All sentences in this paper that are marked with ?? and * are syntactically grammatical, but are unacceptable due to violation of various constraints on empathy foci.
} 
psychology, nowadays, more and more linguists have already realized that empathy plays a significant role in verbal communication. As one of the basic communication processes, empathy is the starting point of an effective interpersonal communication climate that lays the groundwork for responses that clarify meaning and help the other person.

In pragmatics, empathy is that the speaker and the hearer who are involved in the act of communication can detect and identify the immediate affective state of each other and respond in an appropriate manner. The first part of this definition, "detect and identify the immediate affective state of each other", describes the process of perception that is basic to selecting appropriate responses. It follows that empathy requires people involved in the interaction to understand how the others perceive the situation and what their emotional states are. What is more, empathy has a "you" orientation that makes successful interaction possible, rather than "I" orientation that may prevent a positive communication from taking place.

\section{Communicative Competence}

\section{A. Communicative Competence in Language Learning}

Communicative competence is a relatively new concept. Although several scholars (Argyle \& Kendon, 1967; Goffman, 1959) have dealt with communicative competence in various ways, the term first gained wide exposure in the writings of Hymes (1971). He used the term to refer to the knowledge an individual has about the use of language in communication. Since Hymes, a number of individuals have written about communicative competence, but have used a variety of definitions. This lack of definitional and theoretical consistency, though common to concepts in their developmental stages, points to a need for further clarification and elaboration of this concept if a useful theory is to be developed.

Then what is communicative competence? For the connotation of this question, many socio-linguists and anthropologists have their own views. Halliday (1970) points out, it is predominant in our thinking about language that we want it to allow us 'to communicate something, to represent our experience of the processes, persons, objects, abstractions, qualities, states and relations of the world around us and inside us'. According to Noam Chomsky, competence was defined as "the ability of an ideal native speaker to construct and recognize grammatical and only grammatical sentences in his language" (Noam Chomsky, 1965).

In Hymes' theory, he argues that communicative competence must include not only the linguistic forms of a language but also the knowledge of when, how and to whom it is appropriate to use these forms. Hymes (1971) defined communication competence as "the most general term for the speaking and hearing capabilities of a person". Competence is understood to be dependent on two things: (tacit) knowledge and (ability for) use. He pointed out that a normal child acquires knowledge of sentences, not only as grammatical, but also as appropriate.

\section{B. The Relationship between Empathy and Communicative Competence}

The communication process is highly complex and a wide range of factors may contribute to the perception of communicative competence. General conceptions of communication competence are provided by a number of sources. Scholars on intercultural communication view empathy as the means of leaping over the hindrances in intercultural communication, and one component of effective communicative competence. In discussing dimensions of communicative competence, Weinstein (1969) gives a sense of the skills involved:

Skill at establishing and maintaining desired identities both for one's self and for others, is pivotal in being interpersonally competent. This skill is dependent in turn on three variables. First, the individual must be able to take the role of the other accurately; he must be able to correctly predict the impact that various lines of action will have on alter's definition of the situation. This is what is meant by empathy if we strip the concept of its affective overtones.

Therefore, empathy composes one of the necessities for effective communication.

What are intercultural communication competencies that are seen as contributing towards effective communication? A great deal of research aimed at answering this question has been carried out. For example, researchers in Britain and the United States have discussed and listed intercultural competencies that should be taught, together with foreign languages (Byram, 1997). They make the point that foreign language study does not automatically result in intercultural competence.

The most obvious cognitive factors influencing our effectiveness in communicating with strangers are our ability to speak the other language and the knowledge we have about the foreign culture. While it is theoretically possible to communicate effectively with no prior knowledge of the culture from which the strangers come and no ability to speak their language (assuming they can speak ours to some degree), this is obviously not the ideal situation. Even if we cannot speak fluently, our efforts to speak the foreign language probably will be appreciated and will lead to more effective communication. In addition, our knowledge of the strangers' culture and of how it is different from and similar to our own has a direct impact on our interpretations and predictions of their behavior. If we know nothing about the strangers' culture, it is highly probable we will make inaccurate predictions and interpretations of their behavior. Thus, acquiring effectiveness in intercultural communication needs the language and culture knowledge first.

As for the affective component of effective intercultural communication, Gudykunst (1984) argue that people who are effective in communicating with strangers do not use the perspective of their own culture when interpreting the 
behavior of people from other cultures. Rather, effective communicators use a third-culture perspective, which acts as a psychological link between their cultural perspective and that of the stranger:

...we can say that people who have highly developed this perspective can be characterized as follows: (1) they are open-minded toward new ideas and experiences, (2) they are empathic toward people from other cultures, (3) they accurately perceive differences and similarities between the host culture and their own, (4) they tend to describe behavior they don't understand rather than evaluating unfamiliar behavior as bad, nonsensical, or meaningless, (5) they are relatively astute non-critical observers of their own behavior and that of others, (6) they are better able to establish meaningful relationships with people from the host culture, and (7) they are less ethnocentric (i.e., they try first to understand and then evaluate the behavior of host nationals based upon the standards of the culture they are living in).

The following are some examples to show the difference between competent communicators and incompetent communicators in their verbal communication. Among some European Americans, for instance, declarative statements express their personal attitudes or opinions as if they were facts, and an absence of qualifiers or modifiers, would show that they tend to evaluate unfamiliar behaviors rather than describing them:

- "New Yorkers must be crazy to live in that city."

- "Parisians are rude and unfriendly."

" "The custom of arranged marriages is barbaric."

- Every person wants to succeed--- it's human nature."

In contrast, a competent intercultural communicator shows his/her empathy toward other culture, and is open-minded to new experiences, as illustrated in the following examples:

- "I find New York a very difficult place to visit and would not want to live there."

- "Many of the people I interacted with when visiting Paris were not friendly or courteous to me."

- "I would not want my parents to arrange my marriage for me."

" "I want to succeed in what I do, and I think most people do."

In this aspect, empathy ability is a crucial component. It is recognized as an important factor for communication effectiveness not only in the United States but also in other cultures as well.

\section{Ways of Improving Communicative Competence}

Communicative competence is now widely recognized as an important goal of language learning and teaching, and a good deal has been written concerning the necessity of making knowledge about socio-linguistic rules a part of classroom instruction in ESL or, indeed, in any second language. In recent years, many colleges and universities have taken communicative competence as the main aim in foreign language teaching and learning. However, as we have mentioned, communicative competence will not happen naturally, but have to be learned instead, and this is a long and complicated process. To be a competent communicator, one has to prepare from many different aspects. For example, competent intercultural communicators recognize and accept themselves as cultural beings, and understand their own cultural/social identities and how they shape their worldview. This includes an awareness of their own communication style, which reflects their perceptions, assumptions, norms, values, and beliefs. They adjust their style to the situation, communicating very purposefully by keeping the cultural knowledge of the audience in mind. Becoming aware of our own communication style will allow us to improve our intercultural competence. We may also suppose that being aware of the communication style of people from other cultures is also one of the essential components for intercultural competence. Most people have difficulties in bearing the differences of other cultures in some specific aspects such as beliefs, values, attitudes and ways of communicating. Therefore, to allow the existence of differences in different cultures is vital to easy intercultural communication. People usually view others from their own perspectives since judgment cannot be made without individual's experience. People have stereotypes when they offer judgment. When two people from different cultural backgrounds meet to communicate, it will not do so if one party looks down upon the other's custom and even attacks it from his own perspective.

As discussed in the previous section, ethnocentrism is a tendency to judge people unconsciously by the standard of his/her group and his/her own customs. They place themselves, their racial, ethnic or social group at the very center of the universe and rate other people from their own perspectives. Those people believe one group is superior to another, one segment of society to another, one nation/state to another. They usually view their own groups, their own country, and their own culture as the best, the most moral, and the most reasonable. This view often leads to the attitude that my country first - right or wrong. Therefore, if learners of English are to communicate successfully on a personal level with individuals from English-speaking cultures, they need not only to recognize the different cultural patterns at work in the behavior of people from English-speaking countries; they also need to become aware of the ways in which their own cultural background influences their own behavior, and to develop a tolerance for behavior patterns that are different from their own.

Empathy has been defined as "An emotional response that stems from another's emotional state or condition, and involves at least a minimal degree of differentiation between self and other" (Eisenberg \& Fabes, 1990, cited in Larry A. Samovar's Communication Between Cultures). A famous Native American proverb tells us "We should not judge another person until we have walked two moons in his moccasins." That is, we need to develop empathy - be able to see things from the point of view of others. Many researchers in the area of interpersonal and intercultural competence 
believe that our success as communicators depends, to a large extent, on our "skill at establishing and maintaining desired identities for both self and others." "Identities" are actually the pictures of ourselves and the other person that we hold in our heads. We use these pictures in two ways. First, our identities help us to define the messages we receive from others; and second, they assist us in selecting the most appropriate message to send to another person. We need not only know ourselves but also we need to develop empathy (emotional identification) and role-taking (cognitive adaptation) competence so that we can better know and adjust to the other person. After reviewing the literature on the topic of empathy, Broome concluded, "Empathy has been recognized as important to both general communicative competence and as a central characteristic of competent and effective intercultural communication."

Individuals who are able to communicate an awareness of another person's thoughts, feelings, and experiences are regarded as more competent in intercultural interactions. Alternatively, those who lack the ability of showing empathy, and who therefore indicate little or no awareness of even the most obvious feelings and thoughts of others, will not be considered as competent. Empathetic behaviors include verbal statements that identify the experiences of others and nonverbal codes that are complementary to the moods and thoughts of others.

The skill we are describing here is the capacity to behave as if one understands the world as others do. Of course, empathy is not just responding to the tears and smiles of others, which may, in fact, mean something very different than your cultural interpretations would suggest. Although empathy does involve responding to the emotional context of another person's experience, tears and smiles are often poor indicators of emotional states.

However, a number of behaviors can keep us from understanding the feelings, thoughts, and motives of another person - regardless of his or her culture. Perhaps the most common of all barriers to empathy is a constant self-focus. It is difficult to gather information about the other person, and to reflect on that information, if we are consumed with thoughts of ourselves. Attending to our own thoughts, as if they were the only ones that mattered, uses much of the energy that we should direct toward our communication partner. At times we are guilty of behaving according to the German proverb "Everyone thinks that all the bells echo his own thoughts."

Stereotyped notions concerning gender, race, and culture also serve as potential stumbling blocks to empathy. If we believe that "all English people dislike the Irish," we might allow this stereotype to influence our view of an English person. Stereotyped notions are so much a part of our personalities that we must be careful not to allow these unsupported generalizations to serve as our models of other people.

Empathy is best when it is reciprocal; hence, most of us have an aversion to revealing very much to a person who seems uninterested in us and our ideas. Empathy cannot take place when one of the individuals becomes defensive over the other person's lack of interest. Again, we must answer this question: How much do I enjoy talking to a person who shows no interest in me and in what I am saying? Dogmatism is yet another attitude that keeps us from developing empathy. If someone behaved as if he or she had doubted everything we said and had all the answers, even to questions we had not even asked, we probably would become defensive. With a dogmatic person, our defensiveness may take the form of silence or of dogmatism of our own. In either case, this defensive behavior will not be conductive to empathy.

Although it is nearly impossible to know another person completely and accurately, we can, with practice, develop the skills necessary to overcome the problems we have mentioned.

\section{Ways of Improving Empathy for Language Learners}

It is now commonly accepted that a good command of English vocabulary and grammar does not mean a good mastery of English. A student cannot hope to obtain ICC competence without a good knowledge of the culture of the target language.

When a student enters a university, he or she has usually studied English for between ten and twelve years. Furthermore, he or she may have been exposed to English television channels, English daily newspapers, and English movies. So a student at college level may be quite an advanced learner of English. Chinese students tend to achieve linguistic mastery of a foreign language to the point as having a complete knowledge of the language, but fail to achieve a grasp of the culture reflected in that language. Hence lack the proper intercultural communicative competence. They are more successful at acquiring accuracy than appropriateness, which may result in latent errors or misunderstandings. The task for English teaching goes far beyond the teaching of vocabulary and grammar. The goal of improving students' communicative competence inevitably comes to the top of the list that language teachers care about. The separation of language and culture teaching hinders the students' competence acquisition, both linguistic and communicative. Generally, the ELT process is not a dynamic and systematic process in China. What this thesis needs to do is to suggest some ways of improving empathy in the process of cultural learning, hence improving intercultural communicative competence.

\section{PREPARING FOR EMPATHY}

Because empathy is a reciprocal act, we must be expressive in our communication with our partners (unless we are interacting with someone from a culture that values interpersonal restraint). We cannot expect individuals from other cultures to offer us verbal and nonverbal messages about their internal states if our behavior is not in tandem with their efforts.

Empathy can be enhanced through awareness of specific behaviors that members of a particular culture or co-culture 
might find impertinent or insulting.

Empathy can be increased if we resist the tendency to interpret the other's verbal and nonverbal actions from our culture's orientation. What we need to do in order to be more effective is to make a conscious decision concerning our basic attitudes toward ourselves and toward our relationships to others. Learn to suspend, or at least keep in check, the cultural perspective that is unique to our experiences. Knowing how the frame of reference of other cultures differs from our own will assist us in accurately reading what meaning lies behind words and actions. For example, in the Chinese culture, as a means of "saving face," people will often say one thing when they mean something else. Knowing this can help us understand what is actually being expressed.

When two people speaking different languages come together, one of them must speak the language of the other or they must choose a third language that both of them can understand if they are to communicate. However, even though we are going to show our empathy in order to communicate effectively, it is still important for us to maintain our own identity, i.e., being able to "come back from others' shoes". For example, a Chinese may speak English to communicate with an American. He may love the language and the culture, but if the Chinese tries to imitate Americans then he has gone beyond the purpose of showing empathy to his partner. The same case is also true to all foreign language learners in China. Therefore, we need to empathize but at the same time should also try to avoid over-empathizing.

\section{CONCLUSION}

This thesis has referred to quite a few understandings of the concept empathy, which include its definitions in aesthetics and psychology and its application in syntax, pragmatics, and intercultural communication. Since empathy was introduced into linguistics, it has aroused great interest of many linguists. Apart from Kuno's application into syntax, empathy is widely used in intercultural communication, and it is in this field that empathy obtains great practical value.

In a world that foreign language becomes an important tool for intercultural communication, communicative effectiveness is vital for communicators. Many scholars suggest that a relationship exists between an individual's ability to use the communication process and his ability to function in society.

Showing empathy represents an important dimension of communicator's attitudes. It plays both an active and vital role in verbal communication, especially in intercultural communication, for it is an attempt to understand the other person's position and respond as accurately and appropriately as possible. This thesis mainly focuses on the acquisition of intercultural communicative competence by improving empathy ability. Needless to say, the exploration of the phenomenon of empathy in the linguistic field and in intercultural communication only touches a very limited number of aspects. This thesis only intends to offer an introduction to those who are interested in this issue and who wish to make further research.

\section{REFERENCES}

[1] Arasaratnam, Lily A. \& Doerfel, Marya L. (2005). Intercultural Communication Competence: Identifying Key Components from Multicultural Perspectives. International Journal of Intercultural Relations 29: 137-163.

[2] Argyle, M., \& Kendon, A. (1967). The Experimental Analysis of Social Performance. Advances in Experimental Social Psychology 3: 55-98.

[3] Barnlund, D. (1982). Communication in a Global Village. Intercultural Communication: a Reader. Belmont, Calif.: Wadsworth.

[4] Brislin, Richard W., et al. (1986). Intercultural Interactions: a Practical Guide. Newbery Park: Sage Publications.

[5] Byram, M. \& Zarate, G. (1997). Defining and Assessing Intercultural Competence. Language Teaching 29: 14-28.

[6] Davis, M. (1996). Empathy: A Social Psychological Approach. Boulder, CO: Westview Press.

[7] Gao Yihong. (1999). The Recognition and Surpass of the Differences Among Languages, Beijing, Foreign Language Teaching and Research Press.

[8] Gudykunst, William B. (2002). Intercultural Communication. Handbook of International and Intercultural Communication. Thousand Oaks, CA: Sage.

[9] Gudykunst, William B. (2003). Cross-Cultural and Intercultural Communication. London: Sage Publications.

[10] Hall, Bradford 'J'. (2003). Among Cultures: the Challenge of Communication. Belmont: Thomson Learning.

[11] Hall, Edward T. (1973). The Silent Language. New York: Anchor Press.

[12] Kuno, Susumu. (1987). Functinal Syntax: Anaphora, Discourse and Empathy. Chicago: University of Chicago Press.

[13] Levinson, Stephen C. (2001). Pragmatics. Beijing: Foreign Language Teaching and Research Press.

[14] Lustig, Myron W. \& Koester, Jolene (2003). Intercultural Competence: Interpersonal Communication across Cultures. New York: Allon and Bacon Press.

[15] Martin, Judith N. \& Nakayama, Thomas K. (2004). Intercultural Communication in Contexts. New York: McGraw-Hill.

[16] Samovar, Larry A., et al. (2000). Communication between Cultures. Beijing: Foreign Language Teaching and Research Press.

[17] Yang Yue. (2000). The Study of Empathy in Language, Master's Degree Thesis of Jilin University.

[18] Young Yun Kim. (2005). Adapting to a New Culture: Theorizing about Intercultural Communication. London: Sage Publications.

[19] Zhao Dongsheng. (2005). Empathy and Cross-cultural Communication. Journals of Henan University, Volume 4, 95-97. 
Chao Chen was born in Jilin, China in 1977. She received her Master's degree in linguistics from Jilin University, China in 2006.

She is currently an instructor in the School of Foreign Languages, Qingdao University of Science and Technology, Qingdao, China. Her research interests include linguistics and cross-cultural communication. 